\title{
Sutureless aortic valve replacement in patients who have bicuspid aortic valve
}

\author{
Anthony Nguyen, MD, MSc, ${ }^{a, b}$ William Fortin, MD, ${ }^{\mathrm{b}}$ Amine Mazine, MSc, ${ }^{\mathrm{b}}$ Denis Bouchard, MD, PhD, ${ }^{\mathrm{a}, \mathrm{b}}$ \\ Michel Carrier, MD, MBA, ${ }^{\mathrm{a}, \mathrm{b}}$ Ismail El Hamamsy, MD, PhD, ${ }^{\mathrm{a}, \mathrm{b}}$ Yoan Lamarche, MD, ${ }^{\mathrm{a}, \mathrm{b}}$ and \\ Philippe Demers, $\mathrm{MD}^{\mathrm{a}, \mathrm{b}}$
}

\begin{abstract}
Objective: Bicuspid aortic valve (BAV) is generally considered to be a contraindication to sutureless aortic valve replacement (AVR). The aim of this study was to evaluate the feasibility and perioperative outcomes of this technique in patients with BAV.
\end{abstract}

Methods: From June 2011 to January 2014, a total of 25 patients who underwent sutureless AVR had documented BAV. Thirteen patients $(52 \%)$ had median sternotomy, and 12 patients $(48 \%)$ a minimally invasive approach.

Results: The study population included $17(68 \%)$ men with a median age of $77.8 \pm 5.4$ years. The mean EuroSCORE II was $3.4 \% \pm 2.6 \%$. Concomitant procedures included coronary artery bypass grafting in 8 patients $(32 \%), 2$ AVRs $(8 \%), 1$ mitral valve repair $(4 \%), 1$ septal myomectomy $(4 \%)$, and 1 atrial septal defect closure $(4 \%)$. The mean transaortic valve gradient decreased from $49.4 \pm 15.7$, to $14.5 \pm 5.4 \mathrm{~mm} \mathrm{Hg}$ postoperatively. The mean aortic valve area increased from $0.78 \pm 0.18$, to $1.75 \pm 0.43 \mathrm{~cm}^{2}$ postoperatively. Five patients $(20 \%)$ suffered from atrioventricular block that required permanent pacemaker implantation. Two patients ( $8 \%$ ) suffered a stroke. No major paravalvular leakage occurred, and no postoperative valve migration. In-hospital mortality occurred in 1 patient ( $4 \%$ ). The mean intensive care unit length of stay was $3 \pm 2$ days postoperatively.

Conclusions: This study demonstrates that a sutureless aortic valve can be deployed in patients with BAV without increasing the risk of paravalvular leakage. BAV should not be considered a contraindication to sutureless AVR. (J Thorac Cardiovasc Surg 2015;150:851-7)

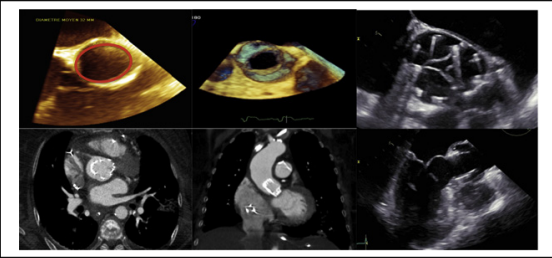

Computed tomographic imaging of sutureless valve deployment in bicuspid aortic valve (elliptic annuli).

Central Message

Bicuspid aortic valve should not be considered to be a contraindication to sutureless aortic valve replacement.

Perspective

The aim of this study was to evaluate the feasibility and perioperative outcomes of sutureless aortic valve replacement in patients with bicuspid aortic valve. The transaortic valve gradient decreased significantly postoperatively with no major paravalvular leakage. Bicuspid aortic valve should not be considered to be a contraindication to sutureless aortic valve replacement.

See Editorial Commentary page 858
Bicuspid aortic valve (BAV) is the most common congenital heart disease and can evolve into aortic stenosis (AS). ${ }^{1}$ The use of sutureless valves is a relatively new tool to treat severe AS in selected intermediate-risk patients. The potential advantages are a shorter aortic crossclamp time, especially in concomitant procedures, and easier implantation, making

\footnotetext{
From the ${ }^{\mathrm{a} D e p a r t m e n t}$ of Cardiac Surgery, Montreal Heart Institute; and ${ }^{\mathrm{b}}$ University of Montreal, Montreal, Quebec, Canada.

This work was funded by The Montreal Heart Institute's Department of Cardiovascular Surgery. No extramural funding supported this work.

Read at the Cardiovascular Valve Symposium at the American Association of

Thoracic Surgery, Istanbul, Turkey, September 4-6, 2014.

Received for publication Feb 3, 2015; revisions received May 14, 2015; accepted for publication May 18, 2015; available ahead of print July 22, 2015

Address for reprints: Philippe Demers, MD, Department of Cardiac Surgery, Montreal Heart Institute, 5000 Belanger St, Montreal, Quebec, Canada H1T 1C8 (E-mail: philippe.demers@icm-mhi.org).

$0022-5223 / \$ 36.00$

Copyright (c) 2015 by The American Association for Thoracic Surgery

http://dx.doi.org/10.1016/j.jtcvs.2015.05.071
}

for minimally invasive surgery. ${ }^{2-4}$ We previously reported excellent early clinical and hemodynamic outcomes with use of sutureless prostheses. ${ }^{5}$ However, AS involving a BAV traditionally has been a contraindication to sutureless valve or transcatheter aortic valve implantation (TAVI), ${ }^{6-13}$ largely because of the anatomic characteristics of the aortic annulus. We describe our experience with the Perceval $\mathrm{S}$ sutureless valve (Sorin, Saluggia, Italy) in patients with BAV.

\section{METHODS}

Between June 2011 and November 2014, a total of 283 patients with severe AS underwent replacement of the aortic valve with the Perceval S valve (Sorin). Among these, $25(8.8 \%)$ patients had a documented BAV. This valve is a new generation of bioprosthesis composed of bovine pericardium mounted on a nitinol cage. The valve is collapsed in a dedicated system for rapid deployment.

Written informed consent was obtained for each patient, and the study was approved by the ethics committee of our institution. All patients were 


$\begin{array}{ll}\text { Abbreviations and Acronyms } \\ \text { AS } & =\text { aortic stenosis } \\ \text { AVR } & =\text { aortic valve replacement } \\ \text { BAV } & =\text { bicuspid aortic valve } \\ \text { EuroSCORE }= & \text { European System for Cardiac } \\ & \text { Operative Risk Evaluation } \\ \text { PPM } & =\text { permanent pacemaker } \\ \text { TAVI } & =\text { transcatheter aortic valve } \\ & \text { implantation }\end{array}$

followed prospectively in our institution's valve clinic. Preoperative data included clinical assessment with a specific analysis of the anatomy of BAV. The diagnosis of BAV was based on short-axis transthoracic or transesophageal ultrasound imaging of the aortic valve, and was confirmed intraoperatively in the presence of 2 commissures delimiting only 2 aortic leaflets. The BAVs were classified based on the presence (type 1) or absence (type 0 ) of raphe. ${ }^{14}$ The severity of AS was defined as the mean transaortic gradient and aortic valve area. Associated regurgitation was evaluated according to published guidelines. ${ }^{15}$

The aortic annulus was measured at the level of insertion of the aortic leaflets. Preoperative echocardiography and perioperative visual observation confirmed the diagnosis and was used to assess the type of BAV, the distribution of calcifications, and the aortic diameter, including the annulus, the sinuses of Valsalva, the sinotubular junction, and the ascending aorta. The technical aspects of Perceval S (Sorin) implantation have been described previously. ${ }^{3-5}$ The procedures were performed by complete sternotomy $(n=13)$, partial sternotomy $(n=5)$, or right minithoracotomy $(n=7)$. All procedures were performed with concomitant transesophageal echocardiography.

A local clinical decision-making algorithm was built to help surgeons in deciding when to use sutureless valves. The algorithm specifies that the valve should be used in patients who: are older than 80 years, can have minimally invasive surgery, have significant calcification of the aortic root, have a left ventricular outflow tract $<21 \mathrm{~mm}$, or are a combined case (AVR + coronary artery bypass grafting; AVR + ascending aortic replacement, etc) with comorbidities and high degree of frailty. When $>2$ of those factors were present, the use of a sutureless valve, although off-label, was still considered, even in BAV.

Postoperatively, all patients received low-dose aspirin, although oral anticoagulation was given if clinically indicated. Imaging follow-up was based on a transthoracic echocardiogram performed before discharge. Adverse events were recorded prospectively. Medical follow-up at 3 months, 6 months, and 1 year with transthoracic echocardiogram control was performed at our institution or by the referring cardiologists.

\section{Surgical Technique}

The technique of sutureless valve implantation has been described previously ${ }^{3-5}$ and is summarized briefly here. Thirteen $(52 \%)$ procedures were performed through a median sternotomy with mild hypothermia $\left(34^{\circ} \mathrm{C}\right)$, cardiopulmonary bypass, and antegrade blood cardioplegia. Five cases $(20 \%)$ were performed through partial sternotomy, and 7 cases $(28 \%)$ through right mini-thoracotomy. The transverse aortotomy was performed approximately $3.5 \mathrm{~cm}$ above the level of the aortic annulus, and $0.5 \mathrm{~cm}$ above the sinotubular junction, to leave a free edge for closure of the aortotomy. The native valve was removed, and annular decalcification was carried out to obtain a homogeneous circular surface to avoid any paravalvular leakage. The aortic ring was measured, and an appropriate-sized prosthesis was chosen.

To better manage the asymmetry of each cusp, the surgeon must recreate 3 nadirs that are positioned at approximately 120 degrees. To achieve this result, the surgeon may use instruments such as a commercial sizer with 120-degree markings to recreate a normal nadir (Figure 1). The selected valve was guided to the correct position using this specific delivery system and 3 polypropylene 4.0 guiding sutures. These sutures were passed through the aortic annulus at the nadir of each aortic leaflet, as described earlier. The valve was delivered and deployed. The delivery systems, as well as the 3 sutures, were removed. After deployment, a dedicated balloon was inserted into the prosthesis and inflated at a pressure of $4 \mathrm{~atm}$ for $30 \mathrm{sec}-$ onds. Once the correct positioning of the prosthesis was visually confirmed, the ascending aorta was closed.

\section{Statistical Analysis}

Data were collected retrospectively from our valve database. Statistical analyses were performed using SPSS, version 20 (SPSS Inc, Chicago, Ill). Continuous variables are presented as mean $\pm \mathrm{SD}$; nominal variables are presented as frequency $(\%)$. Improvements in transaortic gradients and aortic effective orifice area were assessed with the Wilcoxon signed-rank test.

Operative mortality was defined as death within 30 days. For each patient, body surface area was calculated using DuBois' formula and used to determine indexed aortic effective orifice area.

\section{RESULTS \\ Baseline Patient Characteristics}

Between June 2011 and November 2014, a total of 25 $(8.8 \%)$ of 283 patients undergoing sutureless AVR had documented BAV. In this cohort, all bicuspid valves were type 1 . In all patients described, including cases in which the bicuspid valve was discovered intraoperatively, the surgeon implanted the sutureless valve. The basic characteristics of the patients are listed in Table 1 . The mean age was $77.8 \pm 5.4$ years. Seventeen $(68 \%)$ of the patients were men. The mean body mass index was $28.4 \pm 5.1 \mathrm{~kg} / \mathrm{m}^{2}$. The mean predictive logistic EuroSCORE II (European System for Cardiac Operative Risk Evaluation) mortality risk was $3.4 \% \pm 2.6 \%$.

The average systolic pulmonary artery pressure was $34.5 \pm 9.7$ (range: 20 to 53) $\mathrm{mm} \mathrm{Hg}$. Three patients had pulmonary hypertension ( $>50 \mathrm{~mm} \mathrm{Hg}$ systolic) preoperatively. Two $(8 \%)$ patients had a pacemaker before surgery. Preoperative echocardiographic findings were described as follows: the mean aortic valve area was $0.78 \pm 0.18 \mathrm{~cm}^{2}$; the mean aortic gradient was $49.4 \pm 15.7 \mathrm{~mm} \mathrm{Hg}$. Aortic regurgitation was present in 10 patients (grade 1 in 9 patients; grade 2 in 1 patient).

\section{Operative Details}

Details of the procedures are listed in Table 2. Implantation of the Perceval S (Sorin) valve was successful in $100 \%$ of cases. No conversions of minimally invasive surgery into full sternotomy occurred, no replacements for another prosthesis, and no migration or explantation of the sutureless valve. One valve was redeployed.

The mean cardiopulmonary bypass time was $62.2 \pm 16.6$ minutes, and crossclamp time was $49.9 \pm 14.5$ minutes. Concomitant procedures included: coronary artery bypass grafting $(\mathrm{n}=8)$; replacement of 


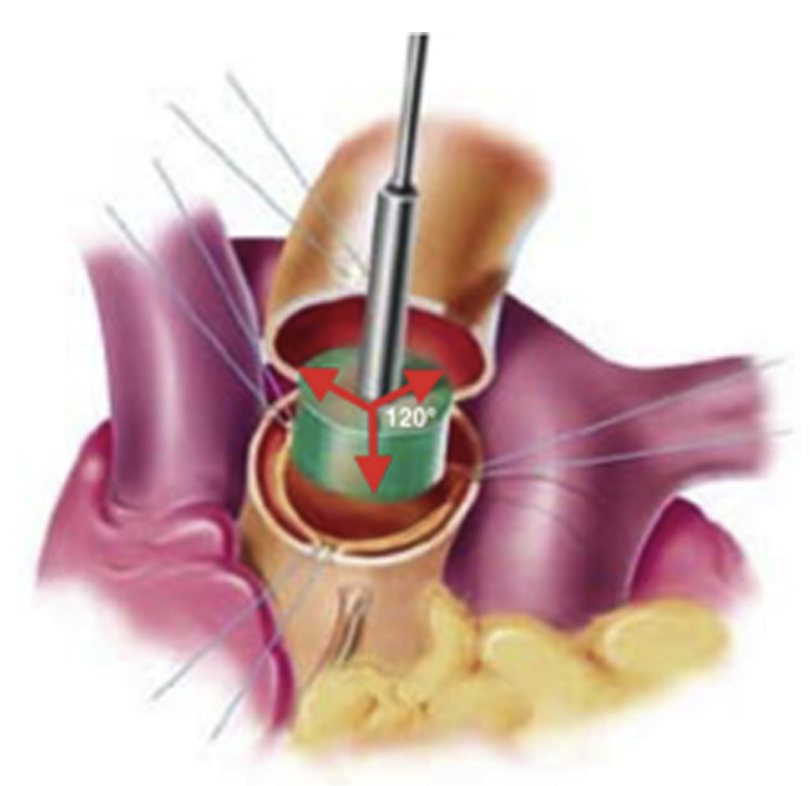

FIGURE 1. Creation of 3 nadirs positioned approximately at 120 degrees with a commercial sizer.

the ascending aorta $(\mathrm{n}=2)$; mitral valve repair $(\mathrm{n}=1)$; septal myomectomy $(\mathrm{n}=1)$; and atrial septal closure $(\mathrm{n}=1)$. The cardiopulmonary bypass times were longer in the combined procedure group $(69.1 \pm 16.8$ minutes $)$ compared with the isolated AVR group $(56.1 \pm 14.9$ minutes $)(P<.001)$. Similarly,

TABLE 1. Patient baseline characteristics

\begin{tabular}{lc}
\hline \multicolumn{1}{c}{ Variable } & Value $(\mathbf{n}=\mathbf{2 5})$ \\
\hline Age $(\mathrm{y})$ & $77.8 \pm 5.4$ \\
Gender, male & $17(68)$ \\
BMI $\left(\mathrm{kg} / \mathrm{m}^{2}\right)$ & $28.4 \pm 5.0$ \\
Comorbidities & \\
$\quad$ Hypertension & $18(72)$ \\
Diabetes & $7(28)$ \\
Hyperlipidemia & $18(72)$ \\
Smoking & $14(56)$ \\
Severe COPD & $7(28)$ \\
Coronary artery disease & $11(44)$ \\
History of stroke/TIA & $0(0)$ \\
Peripheral vascular disease & $4(16)$ \\
Chronic kidney disease & $3(12)$ \\
Previous cardiac surgery & $0(0)$ \\
NYHA class $\geq$ III/IV & $11(44)$ \\
Preoperative rhythm & \\
Atrial fibrillation & $4(16)$ \\
Permanent pacemaker & $2(8)$ \\
Log EuroSCORE II (\%) & $3.4 \pm 2.6$ \\
LVEF (\%) & $59 \pm 5$ \\
Pulmonary artery pressure (mm Hg) & $34.5 \pm 9.7$ \\
\hline Values are M \pm SD, or n (\%). BMI, Body mass index; COPD, chronic obstructive \\
pulmonary disease; TIA, transient ischemic attack; NYHA, New York Heart Associa- \\
tion; EuroSCORE, European System for Cardiac Operative Risk Evaluation; $L V E F$, \\
left ventricular ejection fraction. \\
\end{tabular}

TABLE 2. Intraoperative data

\begin{tabular}{lc}
\hline \multicolumn{1}{c}{ Variable } & Value $(\mathbf{n}=\mathbf{2 5})$ \\
\hline Surgical approach & \\
Full sternotomy & $13(52)$ \\
Ministernotomy & $5(20)$ \\
Minithoracotomy & $7(28)$ \\
Prosthesis size (mm) & \\
Small (21) & $0(0)$ \\
Medium (23) & $4(16)$ \\
Large (25) & $9(36)$ \\
Extra-large (27) & $12(48)$ \\
Isolated AVR & $12(48)$ \\
Concomitant procedures & \\
CABG & $8(32)$ \\
Ascending aorta surgery & $2(8)$ \\
Mitral valve repair & $1(4)$ \\
Septal myectomy & $1(4)$ \\
ASD closure & $1(4)$ \\
Crossclamp time (min) & \\
Isolated AVR & $45.9 \pm 14.0$ \\
Combined procedure & $56.0 \pm 13.7$ \\
CPB time (\%) & \\
Isolated AVR & $56.1 \pm 14.9$ \\
Combined procedure & $69.1 \pm 16.9$ \\
\hline
\end{tabular}

Values are $\mathrm{n}(\%)$ or $\mathrm{M} \pm \mathrm{SD}$, unless otherwise indicated. $A V R$, Aortic valve replacement; $C A B G$, coronary artery bypass grafting; $A S D$, atrial septal defect; $C P B$, cardiopulmonary bypass.

crossclamp times were longer in the combined procedure group $(56.0 \pm 13.7$ minutes) compared with the isolated AVR group $(45.9 \pm 14.0$ minutes $)(P<.001)$. Twelve patients $(48 \%)$ received an extra large-sized valve $(27 \mathrm{~mm}) ; 9$ patients $(36 \%)$ received a large-sized valve $(25 \mathrm{~mm})$; and 4 patients $(16 \%)$ received a medium-sized valve $(23 \mathrm{~mm})$. In 15 patients $(60 \%)$, the indication for AVR was pure AS. In 9 cases $(36 \%)$, the indication was mixed stenosis and aortic regurgitation; and in 1 patient $(4 \%)$, it was isolated aortic regurgitation.

An intraoperative transthoracic echocardiogram showed satisfactory hemodynamic performance of the prosthesis in all patients, without any significant paravalvular regurgitation. Three patients $(12 \%)$ had traces of paravalvular leakage and did not require reoperation.

\section{Perioperative Outcomes}

The median hospital stay from procedure to discharge was 9.48 days (range: 4-50 days). The 30-day combined safety endpoint was achieved in 24 patients $(96 \%)$. The average length of intensive care unit stay was $3 \pm 2$ days. One in-hospital death occurred, due to multiple organ failure on postoperative day 4 (Table 3 ).

No postoperative valve migration was observed. No patients developed myocardial infarction (creatine kinasemyocardial band $>100 \mathrm{UI} / \mathrm{L})$, and 2 patients $(8 \%)$ had a stroke (neurologic deficiency with cerebral damage documented on computed tomography scan). One patient 
TABLE 3. Clinical outcomes

\begin{tabular}{lc}
\hline \multicolumn{1}{c}{ Variable } & Value $(\mathbf{n}=\mathbf{2 5})$ \\
\hline In-hospital mortality & $1(4)$ \\
Valve migration/embolization & $0(0)$ \\
Valve redeployment & $1(4)$ \\
Postoperative explantation & $0(0)$ \\
Endocarditis & $0(0)$ \\
Stroke & $2(8)$ \\
Delirium & $9(36)$ \\
Bleeding requiring reoperation & $1(4)$ \\
Myocardial infarction & $0(0)$ \\
Acute kidney injury* & $6(24)$ \\
Renal replacement therapy & $1(4)$ \\
Atrial fibrillation & $12(48)$ \\
Atrioventricular block & $9(36)$ \\
$\quad$ First degree & $5(20)$ \\
Second degree & $1(4)$ \\
$\quad$ Third degree & $3(12)$ \\
Permanent pacemaker implantation & $5(20)$ \\
ICU length of stay $(d) \dagger$ & $3.0 \pm 2.0$ \\
Hospital stay (d) $\dagger$ & $9.5 \pm 7.0$ \\
\hline Values are $\mathrm{n}(\%)$, or M \pm SD. ICU, Intensive care unit. *Defined as an increase in \\
serum creatinine of $>50 \%$ from baseline. $\dagger$ Calculated for perioperative survivors \\
only.
\end{tabular}

(4\%) had reoperation for excessive mediastinal bleeding, and 6 patients $(24 \%)$ had acute renal failure (serum creatinine level $>50 \%$ ), including 1 patient $(4 \%)$ who required renal replacement therapy (continuous venovenous hemofiltration) postoperatively. Twelve patients $(48 \%)$ developed atrial fibrillation. Implantation of a new permanent pacemaker (PPM) was required in 5 patients $(20 \%)$. In 3 patients $(12 \%)$, indication for a PPM was complete atrioventricular block, resulting from a left bundle branch block in 1 patient, and from sick sinus syndrome in another.

Predischarge transthoracic echocardiography results are presented in Table 4. The aortic valve area increased from $0.78 \pm 0.18$ (range: $0.5-1.3$ ) $\mathrm{cm}^{2}$ to $1.75 \pm 0.43$

TABLE 4. Hemodynamic parameters as measured by TTE

\begin{tabular}{lccc}
\hline \multicolumn{1}{c}{ Variable } & $\begin{array}{c}\text { Preoperative } \\
\text { TTE }\end{array}$ & $\begin{array}{c}\text { Predischarge } \\
\text { TTE }\end{array}$ & $\begin{array}{c}\boldsymbol{P} \\
\text { value*, }\end{array}$ \\
\hline $\begin{array}{l}\text { Peak transaortic gradient } \\
(\mathrm{mm} \mathrm{Hg})\end{array}$ & $72.7 \pm 23.1$ & $26.1 \pm 10.2$ & $<.001$ \\
$\begin{array}{l}\text { Mean transaortic gradient } \\
(\mathrm{mm} \mathrm{Hg})\end{array}$ & $49.4 \pm 15.7$ & $14.5 \pm 5.4$ & $<.001$ \\
Effective orifice area $\left(\mathrm{cm}^{2}\right)$ & $0.78 \pm 0.18$ & $1.56 \pm 0.37$ & $<.001$ \\
$\begin{array}{l}\text { Paravalvular leakage } \\
\text { None }\end{array}$ & - & $22(88)$ & - \\
$\quad$ Mild & - & $3(12)$ & - \\
$\quad$ Moderate-severe & - & $0(0)$ & - \\
LVEF $<50 \%$ & $1(4)$ & $1(4)$ & 1.00 \\
\hline
\end{tabular}

Values are mean $\pm \mathrm{SD}$, or $\mathrm{n}(\%)$, unless otherwise indicated. TTE, Transthoracic echocardiography; $L V E F$, left ventricular ejection fraction. *Calculated using Wilcoxon signed-rank test for continuous variables. †Calculated using McNemar's test for nominal variables. (range: $0.89-2.64) \mathrm{cm}^{2}(P=.01)$, with a decrease in mean aortic gradient from $49.4 \pm 15.7 \mathrm{~mm} \mathrm{Hg}$ (range: $33-76$ ) $\mathrm{mm} \mathrm{Hg}$ to $14.5 \pm 5.4$ (range: $8-30.3) \mathrm{mm} \mathrm{Hg}(P<.0001)$. Three patients $(12 \%)$ had trivial or mild paravalvular regurgitation.

\section{Early Follow-up}

Postdischarge data were obtained from $20(80 \%)$ patients. At a mean follow-up of $12 \pm 8$ months, 2 non-valve-related deaths occurred, giving an overall 1 -year survival of $88 \%$. Among surviving patients, the New York Heart Association functional class at last follow-up was I to IV in $14(87 \%)$ patients, and II to IV in 2 patients. The transthoracic echocardiography at the last follow-up was obtained in 16 survivors, at an average of $14 \pm 6$ months. No migration or structural damage was done to the prosthetic valve. The mean transprothetic gradient was $12.7 \pm 6.4$ (range: $3.6-29$ ) $\mathrm{mm} \mathrm{Hg}$, and the mean aortic valve area was $1.8 \pm 0.6$ (range: 1.0-3.3) $\mathrm{cm}^{2}$. Only 1 patient $(4 \%)$ had mild paravalvular regurgitation. No mitral insufficiency occurred in any patients.

\section{DISCUSSION}

We report the largest series of sutureless AVRs, with the Perceval (Sorin) prosthesis, in patients with BAV. Our results suggest that implantation of this prosthesis in patients with BAV is technically feasible and is associated with satisfactory hemodynamic and clinical results in selected intermediate-risk patients. Despite the recent development of sutureless valves, few reports of clinical experiences have been published on AS in the context of BAV.

Patients with BAV were excluded from clinical trials and considered to be a contraindication for TAVI or sutureless valves. ${ }^{6,7}$ Several factors prevented use of TAVI or a sutureless valve in patients with BAV. ${ }^{16}$ First, aortic annular diameters are often very large. However, appearance of the 31-mm CoreValve System (Medtronic, Minneapolis, Minn), the 29-mm SAPIEN XT valve (Edwards Lifesciences, Irvine, Calif), and the new Perceval XL (Sorin) have partially solved this problem. Second, the asymmetric distribution of calcium may preclude full deployment of the prosthesis by increasing the risk of annular rupture and paravalvular leakage. This problem is particularly likely to occur when excessive radial force is applied to circularize the prosthesis, and it may influence leaflet durability. Third, an association with ascending aorta lesions has limited use of TAVI and sutureless valves in the indications mentioned.

Fourth, implanting a transcatheter valve or a sutureless valve in a noncircular aortic annulus may result in poor sealing and paravalvular regurgitation or valve embolization. Some other groups have published suboptimal TAVI deployment in the case of $\mathrm{BAV},{ }^{16,17}$ suggesting that the 


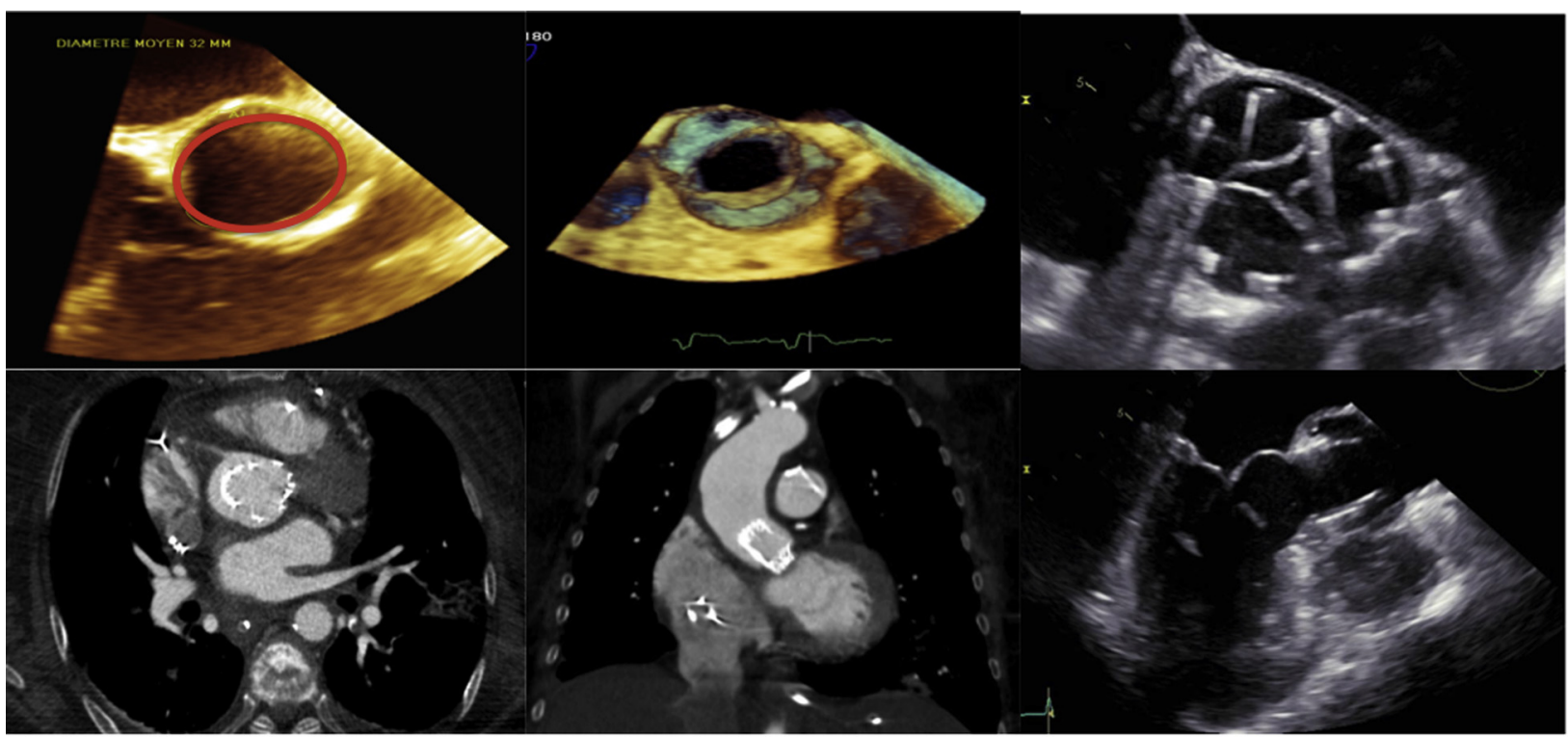

FIGURE 2. Three-dimensional echography and multislice computed tomographic imaging of Perceval S valve (Sorin, Saluggia, Italy) deployment in bicuspid aortic valve (elliptic annuli).

distortion of the valve may be of concern in TAVI implantation. According to them, mainly for geometric reasons, the stent deployed in the case of BAV is elliptic in most cases and may result in earlier deterioration of the valve (Figure 2).

In the present series, the sutureless valve was successfully deployed in all cases (Figure 3). We have shown that the implantation of sutureless aortic valves is feasible in patients at intermediate surgical risk with BAV. Despite the elliptic nature of the aortic annulus, the expansion of the prosthesis was satisfactory, with at most, a degree of aortic regurgitation $\leq 1$, no aortic regurgitation $\geq 2$, and a satisfactory average gradient of $14.5 \pm 5.4 \mathrm{~mm} \mathrm{Hg}$. In the case of Perceval (Sorin) AVR, surgical excision of the native valve is done in conventional fashion, with extensive decalcification of the aortic annulus, preventing, contrary to
TAVI, the possibility of incomplete deployment of the valve.

Furthermore, the sutureless AVR is done under direct visual observation, resulting in a more precise deployment of the valve. Although procedural success was achieved in all patients, 1 intraoperative redeployment of the valve was required. In this particular case, the need for redeployment was caused by malpositioning of the prosthesis in a supra-annular position, defined as the native annulus being visible through the opened prosthetic leaflets.

In 2014, Minh and colleagues ${ }^{5}$ published excellent early clinical and hemodynamic outcomes with use of sutureless prostheses, even in cases of concomitant mitral surgery. The overall survival was $80 \%$, and the mean transaortic gradient and aortic valve area had improved to $11.1 \pm 4.6 \mathrm{~mm} \mathrm{Hg}$ and $1.5 \pm 0.3 \mathrm{~cm}^{2}$, respectively, with no mitral valve

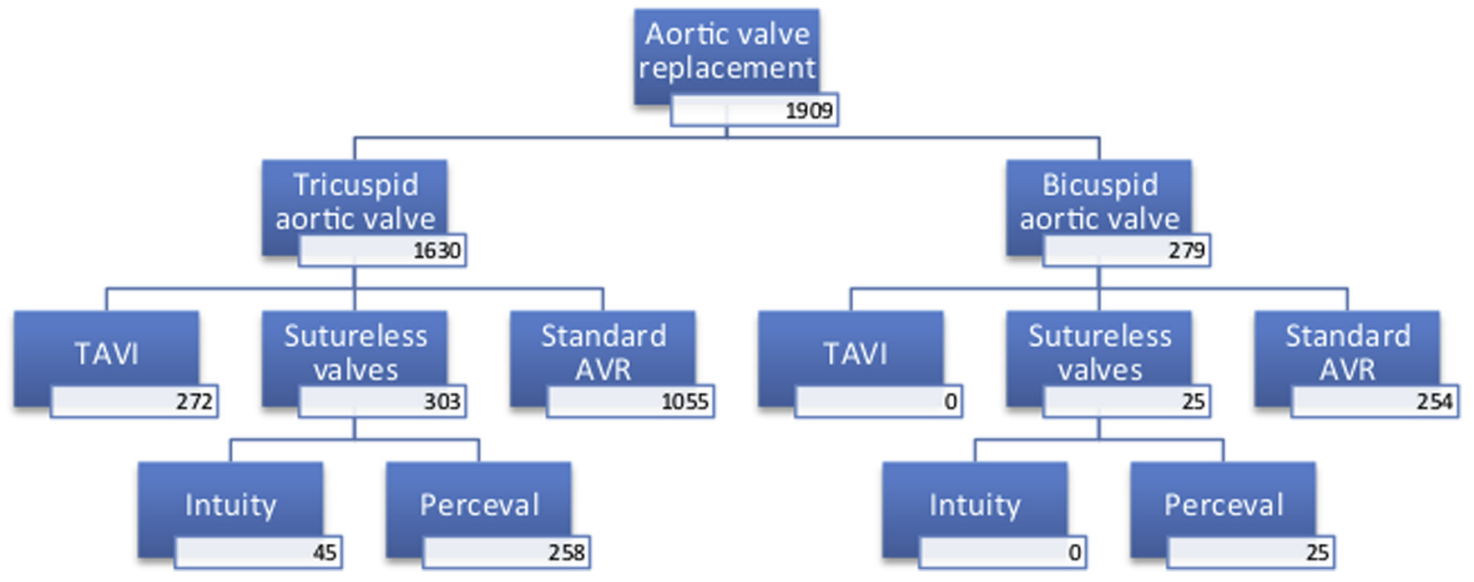

FIGURE 3. CONSORT type outline of aortic valve surgery (2011-2015). TAVI, Transcatheter aortic valve implantation; $A V R$, aortic valve replacement. 
dysfunction. The same study describes the possible causes of prosthesis malposition.

As observed in other series using the Perceval (Sorin), the rate of conduction disturbances requiring pacemaker implantation remained high. $^{5-21}$ As for the CoreValve (Medtronic), the need to implant a PPM is the most frequent event described in the first 30 days after percutaneous AVR $(5.7 \%$ to $20 \%)$. Depending on the type of prosthesis used, its position is between 2 and $6 \mathrm{~mm}$ below the base of the aortic valve leaflets, which can interfere with the atrioventricular node, located very close to the subaortic region and the membranous septum. With the CoreValve (Medtronic), it was shown that patients who needed a postimplantation pacemaker had a significantly lower valve positioned in the ventricle $(10.3 \pm 2.7$ vs $5.5 \pm 3.4 \mathrm{~mm}){ }^{6}$ This complication, although less common, is also available with the SAPIEN XT valve (Edwards Lifesciences) and surgical AVR (2\%-8\%) with the new prostheses. ${ }^{16-20}$

The design of the Perceval (Sorin) is very similar to that of the CoreValve (Medtronic). Khawaja and colleagues ${ }^{22}$ showed in their multicenter observational study that one third of patients $(33.3 \%)$ undergoing a transcatheter CoreValve (Medtronic) aortic valve implantation procedure require a PPM within 30 days. The presence of a periprocedural atrioventricular block, the use of the largest CoreValve (Medtronic) prosthesis, an increased diameter of the interventricular septum, and prolonged QRS duration were associated with the need for implementation of PPM.

In our previous published series, ${ }^{23}$ an incremental increase occurred in risk for postoperative PPM implantation with increasing prosthesis size. The PPM implantation rate was $9 \%, 12 \%, 24 \%$, and $50 \%$ with small, medium, large, and extra-large prostheses, respectively $(P=.02)$, which could be worrisome in the case of BAV. Although this cohort is small, all patients requiring PPM received a Perceval (Sorin), size large or extra-large. Among those, 2 patients had preoperative conduction disorders (right bundle branch block).

In 2014, Santarpino and colleagues ${ }^{24}$ published a propensity-matched study comparing the clinical and echocardiographic outcomes between patients undergoing transcatheter aortic valve implantation (TAVI) and sutureless AVR. Their results showed that in-hospital mortality was similar in the 2 groups $(P=.24)$, as well as pacemaker implantation $(P=.18)$ and neurologic events. However, predischarge echocardiographic data showed a higher paravalvular leakage rate in the TAVI group: $13.5 \%$ versus $0 \%(P=.027)$. At a mean follow-up of $18.9 \pm 10.1$ months, overall cumulative survival was $91.9 \%$ and differed significantly between groups: sutureless, $97.3 \%$ versus TAVI, $86.5 \%(P=.015)$.

Recent results by 2 European centers, including 281 patients who underwent AVR with the Perceval $S$ valve
(Sorin) showed that the overall survival at a median follow-up of 8 months was $90 \%$, with in-hospital mortality of $0.7 \%$, and fewer postoperative complications. ${ }^{25}$ However, longer follow-up and larger trials are needed to determine which specific populations will benefit most from this technology.

Our perioperative PPM implantation rate was previously reported. ${ }^{23}$ Twenty-one percent of patients underwent postoperative implantation of a PPM. The most common indication for pacemaker implantation was complete atrioventricular block (51\%). In our present study on BAV, $60 \%$ of PPM indications were for this type of block $(n=3)$, and 2 were de novo left bundle branch block associated with a low-grade atrioventricular block. Local electrophysiology cardiologists are particularly proactive regarding pacemaker implementation in cases of new electrical disturbances after AVR. Local published data by El-Khally and colleagues $^{26}$ showed that a new and persistent bundle branch block acquired after AVR surgery was the only independent predictor of adverse events during follow-up (odds ratio $8.85 ; P=.0004$ ). The highest event rate was seen in patients who developed new left bundle branch block and left-axis deviation after surgery. A new and persistent bundle branch block acquired after AVR is associated with an increased adverse event rate. This finding suggests that early prophylactic pacemaker implantation should be considered in these patients.

In this series, the rate of perioperative complications was low, especially considering the risk profile of the surgical population. Hemodynamic results were satisfactory at discharge echography and were stable at follow-up with low transprosthetic gradients, the absence of any significant paravalvular leakage, and no evidence of prosthetic dysfunction. Paravalvular leakage disappeared at control echography in 2 patients. Among the 6 patients who developed postoperative acute renal dysfunction, 5 patients had creatinine clearance of $<51 \mathrm{~mL} /$ minute preoperatively. Among those, only 1 patient required temporary renal replacement therapy.

The longer duration of stay in the intensive care unit (>3 days), in 5 PPM postoperative patients, could be explained by local policy stating that patients with complete heart block remain in the intensive care unit until recovery or PPM implantation. In addition, the median length of stay in the intensive care unit was 2 days (range: 0-25 days), and the median duration of hospital stay was 7 days (range: 450 days). Three patients had postoperative complications that required a stay in the intensive care unit for $>15$ days. One in-hospital death occurred at day 4 . The patient was a woman aged 77 years who had chronic obstructive pulmonary disorder and peripheral vascular disease, chronic atrial fibrillation, and critical aortic valve stenosis. The patient developed vasoplegic shock with multiorgan failure unrelated to BAV at day 4. At perioperative transthoracic echocardiogram, the valve was perfectly deployed, 
and the mean aortic gradient was $14 \mathrm{~mm} \mathrm{Hg}$, with no paravalvular leakage. The valve was not identified as a causative factor in the patient's death.

Overall survival at $12 \pm 8$ months was $88 \%$, with no deaths related to the prosthesis. The clinical course was satisfactory with a return to New York Heart Association functional class I in all survivors.

\section{Limitations}

The main limitations of this study are its retrospective nature and lack of a control group. This study is retrospective, single-center, and observational, and was conducted on a relatively small sample of patients. Follow-up is limited, and no conclusion can be drawn regarding the long-term durability of this prosthesis in BAV.

Future studies are needed to confirm our results regarding perioperative outcomes and the need for a PPM. Long-term clinical and echocardiographic follow-up is required.

\section{CONCLUSIONS}

This is the first case series describing sutureless AVR using the Perceval S valve (Sorin) in patients with BAV. In our experience, implantation of this prosthesis in the presence of BAV is a successful and reproducible procedure, leading to satisfactory clinical and hemodynamic results. In elderly patients, extending the indication of sutureless valves to patients with BAV is feasible, with encouraging short-term and intermediate-term clinical outcomes.

\section{Conflict of Interest Statement}

Denis Bouchard and Philippe Demers received lecture fees from Sorin. Denis Bouchard, Philippe Demers, and Michel Carrier are proctors for Sorin. All other authors have nothing to disclose with regard to commercial support.

\section{References}

1. Siu SC, Silversides CK. Bicuspid aortic valve disease. J Am Coll Cardiol. 2010; 55:2789-800.

2. Flameng W, Herregods MC, Hermans H, Van der Mieren G, Vercalsteren M, Poortmans G, et al. Effect of sutureless implantation of the Perceval S aortic valve bioprosthesis on intraoperative and early postoperative outcomes. J Thorac Cardiovasc Surg. 2011;142:1453-7.

3. Ranucci M, Frigiola A, Menicanti L, Castelvecchio S, de Vincentiis C, Pistuddi V. Aortic cross-clamp time, new prostheses, and outcome in aortic valve replacement. J Heart Valve Dis. 2012;21:732-9.

4. D’Onofrio A, Messina A, Lorusso R, Alfieri OR, Fusari M, Rubino P, et al. Sutureless aortic valve replacement as an alternative treatment for patients belonging to the "gray zone" between transcatheter aortic valve implantation and conventional surgery: a propensity-matched, multicenter analysis. $J$ Thorac Cardiovasc Surg. 2012;144:1010-6.

5. Minh T, Mazine A, Bouhout I, El-Hamamsy I, Carrier M, Bouchard D, et al. Expanding the indication for sutureless aortic valve replacement to patients with mitral disease. J Thorac Cardiovasc Surg. 2014;148:1354-9.

6. Vahanian A, Alfieri O, Al-Attar N, Antunes M, Bax J, Cormier B, et al. Transcatheter valve implantation for patients with aortic stenosis: a position statement from the European Association of Cardio-Thoracic Surgery (EACTS) and the European Society of Cardiology (ESC), in collaboration with the European Association of Percutaneous Cardiovascular Interventions (EAPCI). Eur Heart J. 2008;29:1463-70.
7. Holmes DR Jr, Mack MJ, Kaul S, Agnihotri A, Alexander KP, Bailey SR, et al. ACCF/AATS/SCAI/STS expert consensus document on transcatheter aortic valve replacement. J Am Coll Cardiol. 2012;59:1200-54.

8. Wijesinghe N, Ye J, Rodés-Cabau J, Cheung A, Velianou JL, Natarajan MK, et al Transcatheter aortic valve implantation in patients with bicuspid aortic valve stenosis. J Am Coll Cardiol Interv. 2010;3:1122-5.

9. Delgado V, Tops LF, Schuijf JD, van der Kley F, van de Eire NR, Schalij MJ, et al. Successful deployment of a transcatheter aortic valve in a bicuspid aortic stenosis: role of imaging with multislice computed tomography. Circ Cardiovasc Imaging. 2009;2:e12-3.

10. Chiam PT, Chao VT, Tan SY, Koh TH, Lee CY, Tho VY, et al. Percutaneous transcatheter heart valve implantation in a bicuspid aortic valve. JACC Cardiovasc Interv. 2010;3:559-61.

11. Kochman J, Huczek Z, Kotlowski L, Michalak M. Transcatheter implantation of an aortic valve prosthesis in a female patient with severe bicuspid aortic stenosis. Eur Heart J. 2012;33:112.

12. Ferrari E, Locca D, Sulzer C, Marcucci C, Rizzo E, Tozzi P, et al. Successful transapical aortic valve implantation in a congenital bicuspid aortic valve. Ann Thorac Surg. 2010;90:630-2.

13. Jilaihawi H, Asgar A, Bonan R. Good outcome and valve function despite Medtronic CoreValve underexpansion. Catheter Cardiovasc Interv. 2010;76: 1022-5.

14. Sievers HH, Schmidtke C. A classification system for the bicuspid aortic valve from 304 surgical specimens. J Thorac Cardiovasc Surg. 2007;133:1226-33.

15. Zoghbi WA, Enriquez-Sarano M, Foster E, Grayburn PA, Kraft CD, Levine RA et al. Recommendations for evaluation of the severity of native valvular regurgitation with two dimensional and Doppler echocardiography. J Am Soc Echocar diogr. 2003;16:777-802.

16. Zegdi R, Ciobotaru V, Noghin M, Sleilaty G, Lafont A, Latrémouille C, et al. Is it reasonable to treat all calcified stenotic aortic valves with a valved stent? Results from a human anatomic study in adults. J Am Coll Cardiol. 2008;51:579-84.

17. Zegdi R, Lecuyer L, Achouch P, Blanchard D, Lafont A, Latrémouille C, et al Increased radial force improves stent deployment in tricuspid but not in bicuspid native aortic valves. Ann Thorac Surg. 2010;89:768-72.

18. Santarpino G, Pfeiffer S, Concistre G, Fischlein T. A supra-annular malposition of the Perceval sutureless aortic valve: the 'chi-movement' removal technique and subsequent reimplantation. Interact Cardiovasc Thorac Surg. 2012;15:280-1.

19. Roberts WC, Ko JM. Frequency by decades of unicuspid, bicuspid and tricuspid aortic valves in adults having isolated valve replacement for aortic stenosis, with or without associated aortic regurgitation. Circulation. 2005;111:920-5.

20. Roberts WC, Janning KG, Ko JM, Filardo G, Matter GJ. Frequency of congenitally bicuspid aortic valves in patients 80 years of age undergoing aortic valve replacement for aortic stenosis (with or without aortic regurgitation) and implications for transcatheter aortic valve implantation. Am J Cardiol. 2012;109: 1632-6.

21. van Boxtel AG, Houthuizen P, Hamad MA, Sjatskig J, Tan E, Prinzen FW, et al Postoperative conduction disorders after implantation of the self-expandable sutureless Perceval S bioprosthesis. J Heart Valve Dis. 2014;23:319-24.

22. Khawaja MZ, Rajani R, Cook A, Khavandi A, Moynagh A, Chowdhary S, et al. Permanent pacemaker insertion after CoreValve transcatheter aortic valve implantation: incidence and contributing factors (the UK CoreValve Collaborative). Circulation. 2011;123:951-60.

23. Mazine A, Teoh K, Bouhout I, Bhatnagar G, Pelletier M, Voisine P, et al. Sutureless aortic valve replacement: a Canadian multicentre study. Can J Cardiol. 2015; 31:63-8.

24. Santarpino G, Pfeiffer S, Jessl J, Dell' aquila AM, Pollari F, Pauschinger M, et al Sutureless replacement versus transcatheter valve implantation in aortic valve stenosis: a propensity-matched analysis of 2 strategies in high-risk patients. $J$ Thorac Cardiovasc Surg. 2014;147:561-7.

25. Miceli A, Santarpino G, Pfeiffer S, Murzi M, Gilmanov D, Concistre G, et al Minimally invasive aortic valve replacement with Perceval S sutureless valve: early outcomes and one-year survival from two European centers. J Thorac Cardiovasc Surg. 2014;148:2838-43.

26. El-Khally Z, Thibault B, Staniloae C, Theroux P, Dubuc M, Roy D, et al. Prognostic significance of newly acquired bundle branch block after aortic valve replacement. Am J Cardiol. 2004;94:1008-11.

Key Words: aortic valve, replacement, bicuspid aortic valve, bioprosthesis, Perceval S 